\title{
Volvulus of the Sigmoid Colon - A Changing Approach in its Management
}

\author{
Duncan D Mugala \\ BSc, MB ChB, M Med (Surgery), FCS (ecsa), Senior Consultant General Surgeon, Nchanga South Hospital, Chingola.(Retired), Senior \\ Consultant Surgeon Ndola Central Hospital, Senior Lecturer Copper Belt University School of Medicine, Honorary Lecturer University of \\ Zambia School of Medicine. \\ Correspondence: Ndola Central Hospital, Copper Belt University , 6th East wing P O Box 21629 Ndola Zambia
}

\begin{abstract}
Volvulus of the Sigmoid Colon ranks high as a cause of acute abdomen in Africa. Often it leads to intestinal obstruction. The causes of this condition differ from region to region. In the western cultures, volvulus is a disease of the sixth decade: The patients present with abdominal pain, distension, and absolute constipation. The predisposing factors include chronic constipation, mega colon, an excessively mobile colon, Parkinsonism and Psychiatric illness ${ }^{5}$.The African patient may be as young as 15 to 20 years and mainly has a redundant sigmoid colon. What place the diet plays is a matter that is still being debated ${ }^{4,6}$. The golden standard of treatment has come to be as follows; decompression of the Sigmoid volulus with surgical action followed after 48 to 72 hours by resection and anastomosis. The stool is diverted using the Hartman's procedure or the Paul Mickulitz procedure. However, the golden standard is being challenged in favour of a one stage procedure. I present my opinion on this subject
\end{abstract}

Keywords: Anastomosis, Primary, Torsion, Resection, Volulus.

\section{Introduction}

Treatment of Sigmoid Volvulus has been controversial and hasevolved over the past decades from one requiring immediate surgical correction, which carried a high mortality, to one of immediate sigmoidoscopic reduction and elective surgery with its attendant lower mortality. Even from the time of Hippocrates, reduction of the volvulus was attempted using a long suppository ${ }^{6}$

Sir Albert Cook managed Sigmoid Volvulus patients by giving rectal turpentine. Enema and Castor Oil. Hall Crags popularized laparotomy and plication of the redundant loop of colon in the 1950s. This proved ineffective. Some surgeons believe in conservative treatment with tube decompression per rectum only.

Resection of the Sigmoid Colon and construction of colostomy; that is the end or Double barrel- was the next preferred mode of treatment. However, in Africa a Colostomy has adverse social implications. Patients with a Colostomy find it difficult to fit into the society because of poor economies. The management of Colostomies become a problem due to non-availability of Colostomy bags.

Hence a trend towards resection and primary anastomosis started. However, it is argued that; a primary anastomosis in this setting could carry a high incidence of anastomotic leak. Others say primary anastomosis Surgery should reserved for patients in whom tube decompression fails and those in whom the volvulus repeatedly occurs after conservative measures is necessary.

The WHO manual on essential surgical care recommends decompression only ${ }^{5,6,11}$.The golden standard of treatment has come to be; decompression of the Sigmoid Volulus. Surgery is followed after 48 to 72 hours by resection and anastomosis with stool diversion using Hartman's procedure or Paul Mickulitz procedure .However in Africa the reasons stated as above, and the amounting evidence that primary anastomosis of the colon in the emergency situation can be carried out with low morbidity and mortality ${ }^{4}$, the golden standard is being challenged in favour of a one stage procedure $^{10}$.Sule et all carried out this procedure with intraoperative colonic lavage. One would ask the question, what happens if no colonic lavage is done?

Here is presented our experience in the management of this condition in Chingola a Mining Town on the Copperbelt Province of Zambia with a population of over 200,000 people most of whom depend on the mining activities for their livelihood.

\subsection{Patientsand Methods}

This was a prospective study. All patients who presented to Nchanga Mine Hospital from September 1992 to September 1998 with symptoms of torsion of the sigmoid colon were included. Information was collected from the patients and also from the operation notes. This included the ages and sex of the patients, presenting complaints, duration of symptoms, physical findings, investigations and results of investigations, laparotomy findings, procedures done during laparotomy and outcome in terms of length of hospital stay and complications like; anastomotic leakage, wound infection and deaths. The patients were resuscitated; Intravenous Antibiotics prophylaxis in form of Metronidozole and Ampicillin was given.

Some had immediate laparotomy. Some had sigmoidoscopic deflation followed by laparotomy after 72 hours. This depended on the preference of the attending surgeon all the patients who had signs of peritonitis were operated upon immediately after resuscitation. No intraoperative colonic lavage was done in any of our patients. At the end of six years this information was analyzed.

Statistical analysis was also done using the Chi squared test with Yates correction for continuity. 


\section{International Journal of Science and Research (IJSR) \\ ISSN (Online): 2319-7064 \\ Index Copernicus Value (2013): 6.14 | Impact Factor (2014): 5.611}

\section{Results}

\subsection{Age and Sex Distribution:}

During the period of study 50 patients presented with Sigmoid Colon Volvulus. There were 41 males and 9 females, a male to female ratio of 5:1. Their ages ranged from 3 years to 72 years. The mean age was 35.4 years. Five of the patients were in the pediatric age group. The largest number of Sigmoid volvulus patient were those between 31 and 40 years of age. (See Table I)

Table I: Age and sex distribution

\begin{tabular}{|c|c|c|c|c|c|c|c|c|}
\hline Age $\mathrm{Ra}$ & $0-10$ & $11-20$ & $21-30$ & $31-40$ & $41-50$ & $51-70$ & $61-70$ & $71-80$ \\
\hline No. Patí & & 0 & $\begin{array}{ll}0 & 8\end{array}$ & 1 & $\begin{array}{ll}0 & 9\end{array}$ & 0 & 8 & \\
\hline
\end{tabular}

\subsection{Presenting Symptoms}

There were 35 (70\%) patients who presented with acute or acute on chronic symptoms (Hereafter called the acute group).

These were the patients who presented with Intestinal Obstruction.

The patients who presented with chronic abdominal pain (hereafter called the chronic group) without Intestinal Obstruction were 15 (30\%).

The duration of symptoms for the acutely presenting patients ranged from one day to seven days, the average duration was 3.3 days. (See Tables II to IV)

Table II: Symptoms among the acute group.

\begin{tabular}{|l|l|}
\hline \multicolumn{1}{|c|}{ Symptom } & No. of patients (\%) \\
\hline Abdominal Swelling & $35(100)$ \\
\hline Abdominal Pain & $31(91.4)$ \\
\hline Absolute Constipation & $29(82.8)$ \\
\hline Partial Constipation & $06(17.1)$ \\
\hline Vomiting & $11(31.4)$ \\
\hline
\end{tabular}

Table III: Duration of Symptoms in the acute group \begin{tabular}{|l|l|l|l|l|l|l|l|}
\hline Duration of symptoms days & 1 & 2 & 3 & 4 & 5 & 6 & 7 \\
\hline No. of Patients & 9 & 3 & 6 & 5 & 3 & 1 & 4 \\
\hline
\end{tabular}

Table IV: Symptoms of Chronic group

\begin{tabular}{|c|c|}
\hline Symptom & No. of Patients (\%) \\
\hline Abdominal Pain & $13(86.7)$ \\
\hline $\begin{array}{c}\text { Constipation relieved by passing of large } \\
\text { flatus +/- Watery stools }\end{array}$ & $12(80.0)$ \\
\hline Abdominal Swelling some times & $06(40.0)$ \\
\hline Vomiting & $01(6.7)$ \\
\hline
\end{tabular}

In the chronic group of patients the duration of symptoms ranged from 1 year to 5 years. The mean duration was 2 years.

\subsection{Physical Findings}

\subsubsection{The Acute Group}

Twenty eight patients had x-rays of the Abdomen taken which were all diagnostic of sigmoid volvulus. Seven patients were diagnosed clinically the physical findings are shown in Table V.
Table V: Physical findings- Acute group

\begin{tabular}{|c|c|}
\hline Findings & No. of Patients (\%) \\
\hline Abdominal Distension & $35(100)$ \\
\hline Obstructive Bowel Sounds & $35(100)$ \\
\hline Abdominal Tenderness & $9(25.7)$ \\
\hline Shock & $5(14.3)$ \\
\hline Deranged Electrolytes and High BUN & $5(14.3)$ \\
\hline Haemodynamically Stable & $30(85.7)$ \\
\hline
\end{tabular}

\subsubsection{The Chronic Group}

Thirteenpatients (86.7\%) were diagnosed by Barium Enema, two patients by Laparotomy. The barium enema showed a redundant and /or tortuous Sigmoid colon. The two exceptions were diagnosed at Laparotomy done for other reasons. (One patient had a ruptured spleen following a road traffic accident and the other had peritonitis due to appendicitis. Both patients later admitted having intermittent colicky abdominal pain for years). Incidentally two of the patients were brothers: The older brother 35 years, presented with acute symptoms and the younger brother 31 years was the one involved in a road traffic accident and the large redundant colon was discovered at Laparotomy for spleenectomy.

\subsection{Management Strategy}

The acute group were 35patients $(\mathrm{n}=35)$ and the the chronic group of patients were $(n=15)$. In the acute group $23(65 \%)$ patients needed an immediate Laparotomy. Eleven (31, 4\%) patients underwent the Golden standard surgical procedure, Seven $(20 \%)$ of the who underwent Laparotom and four $(11.4 \%)$ out of these declined Laparotomy after decompression. (See Table VI.) Among the chronic group, three patients (25\%) declined surgery. The rest (75\%) were electively operated upon.

Table VI: Laparotomy of the acute group

\begin{tabular}{|c|c|}
\hline Mode of Treatment & No. Patients (\%) \\
\hline Immediate Laparotomy & $23(65.7)$ \\
\hline Laparotomy after decompression & $07(20.0)$ \\
\hline Declined Laparotomy after decompression & $04(11.4)$ \\
\hline Died while being resuscitated & $01(2.8)$ \\
\hline Total No. of Laparotomy & $30(85.7)$ \\
\hline
\end{tabular}

\subsection{Findingsat Laparotomy}

Forty-two patients were laparotomized (30 from the acute group and 12 from the chronic group). The findings were as seen on table VII 


\section{International Journal of Science and Research (IJSR)}

ISSN (Online): 2319-7064

Index Copernicus Value (2013): 6.14 | Impact Factor (2014): 5.611

Table VII: Findings at Laparotomy

\begin{tabular}{|l|l|l|l|}
\hline Findings & $\begin{array}{c}\text { No. of } \\
\text { patients } \\
\text { (\%) } \\
\text { Acute } \\
\text { Group } \\
n=30\end{array}$ & $\begin{array}{c}\text { No. of } \\
\text { Patients } \\
\text { Chronic } \\
\text { Group n } \\
=12\end{array}$ & $\begin{array}{c}\text { Total (\%) } \\
n=42\end{array}$ \\
\hline Redundant Sigmoid Colon & $30(100)$ & $12(100)$ & $42(100)$ \\
\hline Scarring at base of Sigmoid Colon & $30(100)$ & $12(100)$ & $42(100)$ \\
\hline Hypertrophy of Sigmoid Colon & $20(66.7)$ & $07(58.3)$ & $27(64.3)$ \\
\hline Viable Bowel & $23(76.7)$ & $12(100)$ & $35(83.3)$ \\
\hline Gangrenous Bowel & $07(23)$ & 0 & $07(16.7)$ \\
\hline -With small bowel knotting & $03(10)$ & & \\
\hline -Without small bowel knotting & $04(13.3)$ & & \\
\hline
\end{tabular}

\subsection{Procedures Performed}

At laparotomy patients underwent various procedures. These are laid out on Table VII. Please not that during the resection with primary single layer anastomosis; the mucosal exclusion continuous stitch was used.

Table VIII. Procedures Done

\begin{tabular}{|c|c|c|c|}
\hline Procedure* & $\begin{array}{c}\text { No. } \\
\text { Patient } \\
\text { Acute }\end{array}$ & $\begin{array}{c}\text { No. } \\
\text { Patients } \\
\text { Chronic }\end{array}$ & $\begin{array}{c}\text { Total } \\
(\%)\end{array}$ \\
\hline $\begin{array}{c}\text { Resection with primary single layer } \\
\text { anastomosis- No colostomy }\end{array}$ & 17 & 10 & $27(64.3)$ \\
\hline $\begin{array}{c}\text { Resection with primary multiple layer } \\
\text { anastomosis- No colostomy }\end{array}$ & 4 & 1 & $5(11.9)$ \\
\hline $\begin{array}{c}\text { Resection with primary multiple } \\
\text { anastomosis with caecostomy tube }\end{array}$ & 4 & 0 & $4(9.5)$ \\
\hline $\begin{array}{c}\text { Resection primary multiple layer } \\
\text { anastomosis with transverse } \\
\text { colostomy }\end{array}$ & 1 & 0 & $01(2.4)$ \\
\hline Resection with end colostomy & 4 & 0 & $4(9.5)$ \\
\hline No resection done & 0 & 1 & \\
\hline Totals & 30 & 12 & 42 \\
\hline
\end{tabular}

\subsection{The Outcome}

The following were used to determine good or poor outcome.

\subsubsection{Hospital Stay: See Table IX}

Table IX. Outcome following Surgery- Hospital stay

\begin{tabular}{|c|c|c|}
\hline Category & $\begin{array}{c}\text { Range of } \\
\text { Stay In } \\
\text { Days }\end{array}$ & $\begin{array}{c}\text { Mean } \\
\text { Stay In } \\
\text { Days }\end{array}$ \\
\hline Acute group cases & $7-56$ & 16.7 \\
\hline Chronic group cases & $8-14$ & 10 \\
\hline Resection with primary single layer anastomosis & $4-14$ & 9.9 \\
\hline $\begin{array}{c}\text { Resection with primary multiple layer } \\
\text { anastomosis }\end{array}$ & $10-11$ & 10.3 \\
\hline Primary anastomosis caecostomy tube & $21-42$ & 26.6 \\
\hline Resection with colostomy & $21-56$ & 33.3 \\
\hline Immediate surgery after resuscitation & $7-12$ & 10.1 \\
\hline Surgery after deflation & $4-30$ & 13.1 \\
\hline \multicolumn{2}{|c|}{}
\end{tabular}

\subsubsection{Complications}

Table X. Complications

\begin{tabular}{|c|c|c|}
\hline Complications & $\begin{array}{c}\text { No. of } \\
\text { Patients }\end{array}$ & Comment \\
\hline $\begin{array}{c}\text { Wound } \\
\text { Infection }\end{array}$ & 2 & $\begin{array}{c}\text { Ecolab infection 1 Staph. Aurous } \\
\text { infection 1 in patients who presented } \\
\text { with gangrene of bowel }\end{array}$ \\
\hline $\begin{array}{c}\text { Anastomotic } \\
\text { leakage }\end{array}$ & 1 & $\begin{array}{c}\text { Primary anastomosis attempted in } \\
\text { patient with gangrenous bowel at } \\
\text { presentation. }\end{array}$ \\
\hline $\begin{array}{c}\text { Severe weight } \\
\text { loss }\end{array}$ & 1 & $\begin{array}{c}\text { This patient turned out to be TB } \\
\text { abdomen. }\end{array}$ \\
\hline Mortality & 1 & $\begin{array}{c}\text { The patient died while being } \\
\text { resuscitated. }\end{array}$ \\
\hline
\end{tabular}

\subsubsection{Statistical analysis of the outcomes looking at length of stay}

Table XI. P.Values of out come comparison

\begin{tabular}{|c|c|}
\hline Comparison & P. Value \\
\hline $\begin{array}{c}\text { Acute cases Vs chronic cases } \\
\text { Primary Single layer Vs Primary multiple layer } \\
\text { anastomosis }\end{array}$ & 0.95 \\
\hline $\begin{array}{c}\text { Surgery immediately after resuscitation Vs surgery } \\
\text { after deflation }\end{array}$ & 0.99 \\
\hline $\begin{array}{c}\text { Primary anastomosis with caecostomy diversion Vs } \\
\text { resection with colostomy }\end{array}$ & 0.05 \\
\hline $\begin{array}{c}\text { Presence of gangrene of bowel Vs presence of Viable } \\
\text { bowel }\end{array}$ & 0.01 \\
\hline $\begin{array}{c}\text { Primary anastomosis without diversion of stool Vs } \\
\text { Stool diversion by colostomy, caecostomy or } \\
\text { T/Colostomy }\end{array}$ & 0.01 \\
\hline
\end{tabular}

\section{Discussion}

This study showed that volvulus of the sigmoid colon affected people over a wide age range (3 years to 72 years) with the mean age being 35.4 years. When compared to other studies, our patients were generally a younger ${ }^{2,6}$. In fact over $55 \%$ of the sufferers were below 40 years old (Table I). The most affected were the $30-40$ age group. More males were affected than females (M: F 5.1).

The patients were divided into two groups. First, there were those who presented acutely in whom intestinal obstruction was the main feature with typical symptoms (Table II) most of these presented to the hospital early but there were however late presenters as well, for example four patients came to hospital one week late. (Tables III).

There was a second group (30\%) which presented with intermittent abdominal pain running over a prolonged period with a mean duration of two years. The abdominal pain was associated with constipation and relief came after passage of a large flatus in some cases accompanied by watery stools (Table IV). This group had the same findings at Laparotomy as the acute group i.e. scarring at the base of the Sigmoid Colon drawing the two limbs of the colon close together and thus reducing the $\mathrm{x}$-axis (Bruusgaard first noticed this pathology in $1947^{2,4}$ ), then there was the presence of the redundant Sigmoid colon and the thickening of the bowel wall - This was not found in all the cases (Table VI) but it was found in both groups, we note however that the patients 


\section{International Journal of Science and Research (IJSR) \\ ISSN (Online): 2319-7064 \\ Index Copernicus Value (2013): 6.14 | Impact Factor (2014): 5.611}

with chronic symptoms were less likely to have thickening of the bowel wall than the acute group. All these findings show that this is the same disease process in both groups. It is our belief that this group must be identified and offered prophylactic surgery ${ }^{1,3}$; which we did. There was an acceptance rate of $80 \%$. . What makes some patients develop acute or acute on chronic presentation ( $70 \%$ in this study) and some to run a chronic course is a matter yet to be unraveled.

Children are known to develop sigmoid volvulus and they tend to present with chronic abdominal pain. The three years child was one of these patients, four other patients though older were in the pediatric age group (Table I). Sadovsky published a case of a seven years old child with symptoms running for one year, similarly Campbell and Blank had one child who was aged six years at the onset of the illness and was treated only after two years ${ }^{7,9}$.

It is curious that two of our patients were brothers. Could it be that this illness runs in families?

All the patients were in good condition at presentation except for five patients who presented with shock and electrolyte imbalance. Four of the patients with electrolyte imbalance had gangrenous bowel. However three other patients presented with gangrene of the bowel but were in good condition at presentation in that they did not have haemodynamic instability. Gangrenous bowel is always an important factor in sigmoid colon Volvulus. The cause is not always due to knotting as was shown in this study (Table VII). The fact that most of our patient were reasonably fit is a significant issue to note, it indicates that these patients can undergo definitive surgery from the start. Sule et al took advantage of this and carried out the one stage procedure ${ }^{10}$.

The main stay of treatment in these patients was surgery as $84 \%$ of the patients underwent laparotomy. In the acute group $65.7 \%$ were operated on immediately after resuscitation. Of the 11 patients who had sigmoidoscopic decompression, 4 (36.4\%) declined surgery. When the pain has been relieved some patients become non compliant. Faranisi found a non-compliance rate of $25 \%$, Turan et al had a non compliance of $51.3 \%$. This is the number one draw back of sigmoidoscopic decompression whether done with a rigid sigmoidoscope or a fiberoptic one ${ }^{3,8}$.

What must be noted is that this problem has a tendency to recur. Even if these patients do not obstruct, for a long time they will still have the problem of intermittent abdominal pain (Table IV). We note here that even among the chronic group $20 \%$ declined prophylactic surgery. It seems there will always be patients who will decline surgery whether they present acutely or chronically. Our aim is to reduce on these non-compliers. We propose that the Golden stand procedure should be discouraged and a resection and primary anastomosis should be done.It is indeed our standard.

In our practice we preferred the immediate laparotomy after resuscitation over decompressing the patient first(Table VII) in acute presenters and we found that to decompress the patients and then do surgery conferred no advantage over immediate laparotomy after resuscitation in terms of
Hospital stay and complications $(\mathrm{P}=0.99)$. In fact the immediate surgery stayed 7 to12 days compared to the decompressed patients who tended to have a longer hospital stay (Table VIII). Sule ET all also showed a similar picture $^{10}$.

It was also our experience that resection and primary anastomosis was better than surgery with stool diversion $(\mathrm{P}=0.01)$. The patients with stool diversion of any kind stayed longer in hospital (Table VIII). The traditional multiple layer Anastomosis did not have an advantage over single layer anastomosis $(\mathrm{P}=0.99)$. In fact patients, in whom single layer anastomosis was done, went home a day earlier then the multiple layer group. Patients, who presented with gangrene of the bowel, fared worse than those who did not present with gangrene. The best procedure for these patients was resection of the gangrenous bowel with stool diversion. In our experience, doing a resection of the colon, primary anastomosis and large bore protective caecostomy tube was better than doing a colostomy $(\mathrm{P}=0.05)$. On the whole, it is our view that patients who present with Sigmoid volvulus Should have resection of the Sigmoid Colon with primary anastomosis, unless they present with gangrene of the bowel. When we compared the outcome in terms of hospital stay between the acute and chronic presenters the latter stayed 10 days on average and the acute presenters stayed 16.7 days on average. But the difference was not statistically significant.

\section{Conclusion}

The conclusion from this is that it is better to identify these patients before they present acutely i.e. with intestinal obstruction, and operate on them because the signs and symptoms are always there. We did have a mortality of one patient who died while being resuscitated this was one of the patients who presented after seven days. The one anastigmatic leak and the two wound infections all came from among the patients who presented with bowel gangrene. On the whole there was a complication rate of $10 \%$.

We have shown that some patients present with large bowel obstruction creating an acute abdomen (70\%) and yet there is a small group of $30 \%$ who present with chronic abdominal pain, we believe these patients should be identified and given prophylactic surgery. We have demonstrated that in those patients with intestinal obstruction due to sigmoid volvulus, immediate surgery after resuscitation with primary single layer anastomosis without stool diversion is a better option. Intraoperative colonic lavage was not done in our patients. We have also shown that patients who present with gangrene of the bowel, the resection with end to end anastomosis with caecostomy is a better option than the creation of a colostomy.

\section{References}

[1] Walakira J S, Primary resection in the management of Volvulus. Proc Assoc Surg East Afr 2:238

[2] Ejumu M, Early resection of the Sigmoid Colon following Volvulus. Proc Assoc Surg East Afr 8:89 - 91 


\section{International Journal of Science and Research (IJSR) \\ ISSN (Online): 2319-7064}

Index Copernicus Value (2013): 6.14 | Impact Factor (2014): 5.611

[3] Faranisi C T: Primary resection and anastomosis for Sigmoid Volvulus. Proc Assoc Surg East Afr 12:15 174.

[4] Madiba T E . Thomson S R. The management of sigmoid volvulus J.R.Coll.Surg.Edinb., 45, April 2000, 74-80

[5] Khan A N, Howat J .Sigmoid Volvulus. /www.emedicine.com/radio/topic636.htm June 10, 2004

[6] Ballantyne G H. Laparoscopic treatment of volvulus of the colonIn: GHBallantyne, PF Leahy, IM Modlin, Laparoscopic Surgery, W.B. Saunders Co., Phildelphia, 1994.

[7] SADOVSKY RPediatric. Sigmoid Volvulus in Children and Adolescents. American family physician Dec 1 2000.

[8] Turan M,Sen M,Karadayi K,Koyuncu A Topcu O Yildiric C Duman M. Our sigmoid colon volvulus experience and benefits of colonoscope in detortion process.Rev Esp Enferm Dig. 2004 Jan; 96(1):32-5

[9] Campbell J R Blank E. SigmoidVolvulus in Children. Pediatrics Vol. 53 No. 5 May 1974; pp: 702-705 10.

[10] Sule A Z, IyaD, . Obekpa P O, Ogbonna P, . Momoh J T and. Ugwu $B$ T. One-stage procedure in the management of acute sigmoid volvulus. J.R.Coll.Surg.Edinb., 44, June 1999, 164-6

[11]WHO. Sigmoid volvulus. In: WHO eds Essential surgical care manual, abdomen. 